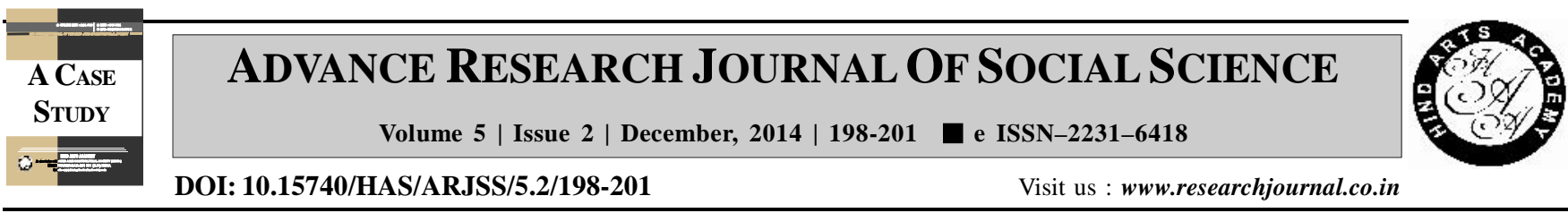

\title{
Study on the village health and sanitation committee (VHSC) in Tumkur district of Karnataka, India
}

\author{
N. Kumara* and Nehal A. Farooquee
}

Department of Extension and Development Studies, Indira Gandhi National Open University, NEW DELHI (INDIA)

(Email: nkumar278@gmail.com)

\section{ARTICLE INFO :}

$\begin{array}{lll}\text { Received } & : & 21.07 .2014 \\ \text { Accepted } & : & 13.11 .2014\end{array}$

\section{KEY WORDS :}

Community participation, VHSC, Village health plan

\section{HOW TO CITE THIS ARTICLE :}

Kumara, N. and Farooquee, Nehal A. (2014). Study on the village health and sanitation committee (VHSC) in Tumkur district of Karnataka, India. Adv. Res. J. Soc. Sci., 5 (2) : 198-201.

*Author for correspondence

\begin{abstract}
Village health and sanitation committee (VHSC) was constituted to institutionalize community participation in key health related issues and is an important move to decentralize and provides an opportunity for grass root level convergence. It is important that the VHSC be strengthened to ensure that the true spirit of community participation is ensured. VHSC is providing universal access to equitable, affordable and quality health care, especially for the poor and vulnerable communities in rural areas, through greater involvement of the Panchayat Raj Institutions (PRI). According to the Government of India guidelines, these committees are recommended to have 50 per cent women representation and representation by scheduled castes, scheduled tribes and other backward classes. This committee also receives an annual untied fund of Rs. $10,000 /$ - for specific activities. The study has clearly shown that expenditure of 98.28 per cent was spent for the purpose of providing rural health services and rural health plans were prepared. Involvement of ASHA workers in VHSCs was maximum of (88.88\%) followed by the President of VHSCs and least participation of S.C., S.T. and women members was recorded.
\end{abstract}

